\title{
Management of Overlap Syndrome between Functional Dyspepsia and Irritable Bowel Syndrome by Western and Traditional Chinese Medicine
}

\author{
Fan Chen \\ Department of Gastroenterology, Fuzhou General Hospital, Fuzhou, China \\ Email: yangqh4848@sina.com
}

How to cite this paper: Chen, F. (2017) Management of Overlap Syndrome between Functional Dyspepsia and Irritable Bowel Syndrome by Western and Traditional Chinese Medicine. Yangtze Medicine, 1, 117-126.

https://doi.org/10.4236/ym.2017.12012

Received: April 12, 2017

Accepted: June 19, 2017

Published: June 22, 2017

Copyright $\odot 2017$ by author and Scientific Research Publishing Inc. This work is licensed under the Creative Commons Attribution International License (CC BY 4.0).

http://creativecommons.org/licenses/by/4.0/

\begin{abstract}
The overlap syndrome of functional dyspepsia and irritable bowel syndrome (FD-IBS) is very common and difficult to treat. There are many risk factors of FD-IBS. Mental illness of FD-IBS patients is more serious. Functional dyspepsia and irritable bowel syndrome have some similarities in the aspects of pathophysiology, pathogenesis, and treatment. We should pay attention to two aspects of the treatment of overlap syndrome, one is simplifying medications, the other is using gastrointestinal motility drug with bidirectional regulative function when necessary. Traditional Chinese medicine in this respect shows some advantages. This review addresses the epidemiology, risk factors, clinical features, pathogenesis and management of FD-IBS.
\end{abstract}

\section{Keywords}

Functional Dyspepsia, Irritable Bowel Syndrome, Overlap Syndrome

\section{Introduction}

Both functional dyspepsia (FD) and irritable bowel syndrome (IBS) belong to functional gastrointestinal diseases (FGIDs). Recent data [1] suggested that overlap between functional dyspepsia and irritable bowel syndrome (FD-IBS) is very common, and there is a growing emphasis on it. The following is a review on epidemiology, risk factors, clinical features, pathogenesis and management of FD-IBS.

\section{Epidemiology}

The prevalence of FD-IBS is reported to be remarkably high in Asian countries. 
Perveen et al. [2] carried out a 3,000-participant survey on the overlap of FD and IBS. The study demonstrated that approximately $27.1 \%$ of IBS patients and $42.1 \%$ of FD patients had FD-IBS, respectively. In addition, based on Rome III criteria, other epidemiology study [3] investigated 3,014 patients who responded to their questionnaires at a general gastroenterology outpatient clinic. The result showed FD-IBS overlap was observed in $5.0 \%$ of the patients, while $31.5 \%$ of IBS patients and $24.8 \%$ of FD patients had FD-IBS.

\section{Risk Factors}

Several studies reported that genetic factors were associated with the incidence of FD-IBS. The CC genotype of G-protein $\beta 3 \mathrm{C} 825 \mathrm{~T}$ may be related to FD and diarrhea-predominant IBS (IBS-D) [4]. In addition, it was found that poor sleep quality, smoking, anxiety, depression, female gender, abdominal distension, lose weight, visceral hypersensitivity and infection were all risk factors for FD-IBS [3] [5]-[10].

Kong and colleagues found that, when compared with single IBS group, mental factors, medications, fatty meal, cold food, climate-related factors and surgical trauma should be valued as predisposing factors of FD-IBS. In terms of drugs, the main cause are laxative agents as well as non-steroidal anti-inflammatory drugs. For example, for some patients with constipation-predominant irritable bowel syndrome (IBS-C), the onset was resulted from long-term use of Chinese and Western medicines such as phenolphthalein tablets, senna granules, and rhubarb soda tablet. Moreover, health care, cosmetics, such as intestinal tea and Paiduyangyan capsule are important factors in this disease [11].

\section{Clinical Features}

Fan et al. [12] reported that, in patients with FD and IBS overlap, postprandial distress syndrome (PDS) group overlap ratio of IBS-C was higher than that of epigastric pain syndrome (EPS) group, while EPS group overlap ratio of IBS-D was higher than that of the PDS group. Another study showed that, when compared with single FD or IBS patients, patients with FD-IBS scored significantly higher in the mental health test than patients with IBS only. Furthermore, the proportion of patients with anxiety and depression in FD-IBS group was higher than that of no overlapping symptoms group [13]. The results indicated that mental conditions of FD-IBS patients were more serious pointing to the notion that the treatment of mental and psychological factors should be strengthened.

\section{Pathogenesis}

Some studies [14] [15] [16] suggested that the mechanisms of FD-IBS include visceral hypersensitivity, gastrointestinal motility dysfunction, genetic susceptibility, psychiatric comorbidities, post-infection sensitization of gastrointestinal tract, and possibly sensitization of central nervous system (see Table 1) [15]. These study indicated that FD and IBS had some similarities in terms of their 
Table 1. Levels of evidence for pathophysiological mechanisms common to functional dyspepsia (FD) and irritable bowel syndrome (IBS).

\begin{tabular}{ccc}
\hline Mechanism & IBS & FD \\
\hline Visceral hypersensitivity & +++ & +++ \\
Upper Gastrointestinal dysmotility & + & +++ \\
Lower Gastrointestinal dysmotility & +++ & + \\
Brain Processing abnormalities & ++ & + \\
Genetics & + & + \\
Psychiatric comorbidities & ++ & + \\
Post-infection & ++ & + \\
Serotonin Signalling abnormalities & + & + \\
\hline
\end{tabular}

+++ , strong evidence, numerous clinical studies in substantial agreement; ++ , moderate evidence, clinical studies in agreement with preliminary data to be confirmed; + , weak evidence, isolated reports, data to be confirmed; ?, no evidence.

pathophysiology and treatment, Just one is located in the stomach, whereas the other is located in the intestines. In this regard, since FD and IBS have a lot of overlap in symptoms which sometimes are not being completely separated, some scholars advocates the expansion of the symptoms of IBS to upper digestive tract, and even called "one irritable gut" [17].

\section{Medical Therapy}

Taking into account the similarities of FD and IBS in pathophysiology and pathogenesis, as well as the complexity of FD-IBS in the clinical treatment, attention should be paid to two aspects of the treatment of overlap syndrome. First, to minimize the adverse drug reactions, medications must be simplified. We should strive for using some medicine which may have effect on both FD and IBS, so as to obtain satisfactory efficacy by using the least kind drugs. Secondly, because gastrointestinal motility disorders of FD and IBS may not be consistent, or even the opposite, gastrointestinal motility drug with bidirectional regulative function should be used. It is worth noting that traditional Chinese medicine in this respect shows some advantages. The following are to be described separately from the Western and Chinese medicine treatment.

\subsection{Western Medicine Therapy}

\subsubsection{The Drugs with Effects on Both FD and IBS}

\section{1) Acid-Suppressive Drugs}

The drugs include $\mathrm{H}_{2}$ receptor antagonists $\left(\mathrm{H}_{2}-\mathrm{Rb}\right)$ and proton pump inhibitors (PPI). They can inhibit gastric acid to relieve both the symptoms of FD patients with upper abdominal pain and IBS-D symptoms [18]. For example, the main mechanism of ranitidine in treatment of IBS-D is as follows. In patients with IBS, their intestinal mucosal mast cells are increased, activation and degranulation, and participate in the pathogenesis of IBS [19]. Ranitidine is a potent 
histamine $\mathrm{H}_{2}$ receptor blockers, and may alleviate the symptoms by inhibiting the release of histamine from intestinal mast cells [20]. Moreover, ranitidine acts with related receptors, resulting in reduced gastric acid secretion. By decreasing the secretion of gastric acid, it can not only reduce gastric acid irritation of the gastrointestinal tract slowing down small bowel peristalsis, but also reduce the overall gastrointestinal secretion of sodium and water leading to decreased gastrointestinal contents. Therefore it can effectively reduce stool frequency, and ultimately achieve the goal of diarrhea. Omeprazole may also be play a role through anti-secreting effect. Furthermore, the chemical structure of omeprazole is similar to that of metronidazole, hence it can play a similar role through some antibacterial effect [21].

However, because of very strong acid suppressive effect of $\mathrm{H}_{2}-\mathrm{Rb}$ and PPI, strong and sustained inhibition of gastric acid may have an impact on digestive function and intestinal microecology, and the longer the impact will be more obvious. And then it may appear adverse reactions such as small intestinal bacterial overgrowth (SIBO), Clostridium difficile-associated diarrhea and microscopic colitis. These may worsen IBS symptoms [22]. Therefore, close monitoring is required at the time of treatment.

\section{2) Probiotics}

Probiotics is not only for the treatment of irritable bowel syndrome, but also has the following three advantages. First, probiotics is able to inhibit Helicobacter pylori (H. Pylori) infection. The possible mechanisms include the downregulation of $\mathrm{H}$. Pylori distribution density, secreting bacteriocins and other substances which kill $\mathrm{H}$. Pylori directly, and inhibiting the in vivo immune response [23]. To our knowledge, H. Pylori is one of the important causes of FD. Secondly, probiotics itself can treat FD by relieving symptoms of FD [24]. Thirdly, probiotics can also prevent SIBO and other intestinal microflora disorders which are caused by PPI [25]. Thus the treatment of PPI can be carried out smoothly.

\section{3) Gastrointestinal Motility Regulation Agents}

For upper and lower gastrointestinal motility disorders whose motility changes are consistent with the same situation, such as the hypokinesis state of gastrointestinal tract when delayed gastric emptying FD appears simultaneously with IBS-C, or the hyperdynamic state of gastrointestinal tract when accelerating gastric emptying FD occurs with IBS-D, we can use gastrointestinal motility inhibitor or prokinetic drugs which have unidirection regulative function. For upper and lower gastrointestinal motility disorders whose motility changes are in inconsistency or paradoxical situation,, such as delayed gastric emptying FD combining with IBS-D, or accelerating gastric emptying FD combining with C-IBS, as well as FD combining with mixed type IBS (IBS-M), We recommend using gastrointestinal motility drugs which have bidirectional regulating function, such as trimebutine or pinaverium bromide [26] [27] [28] [29]. Moreover, there are few drugs which have inhibitory effect both on stomach and intestine peristalsis, and their adverse reactions are frequently observed. Hence, for FD-IBS patients with hyperdynamic state of gastrointestinal tract, trimebutine or 
pinaverium bromide, or gastrointestinal motility inhibitor (effective only for IBS-D) can be used.

\section{4) Antipsychotic Drugs}

The pathogenesis of FD and IBS both include psychological abnormality and visceral sensitivity, and mental factors are even more serious when FD and IBS are overlap [13]. Therefore, antidepressants or anti-anxiety medications should be given. The use of those drugs improve the mental and psychological abnormality, increase the pain threshold to relieve upper abdominal or lower abdominal pain, and improve other symptoms of FD and IBS [30]. In addition, when necessary, those drugs can be combined with psychological therapy [31].

\section{5) Gastrointestinal Mucosal Protective Agents}

The drugs include glutamine [32] [33], rebamipide [34] [35], teprenone [36], and some others. They have a protective effect on gastrointestinal mucous membrane. Hence, they may improve symptoms of patients with FD-IBS. They can be used as appropriate.

\subsubsection{The Drugs for FD or IBS}

The drugs with specified properties, are used separately for FD or IBS. We should use them mainly in the condition when the symptoms of FD and IBS are serious or when the effect of drugs for both FD and IBS is poor. That is to say, according to the severity of FD or IBS, or according to the treatment effect, we should adjust or strengthen the use of drugs from a different focus on the basis of the above treatment. The principle of specific medication is as follows. If the patient's condition is serious, we could use these drugs immediately; and if the patient is not seriously ill, then we could decide whether to use these drugs based on efficacy.

\section{1) Treatment of FD}

The treatment of FD includes $\mathrm{H}$. Pylori eradication, digestive enzymes, and gastric mucosal protective agents [37] [38].

\section{2) Treatment of IBS}

According to some recent reviews [39] [40], we can treat IBS as follows :for IBS-D, the drugs mainly include antidiarrheals, non-absorbable antibiotic, antispasmodics, and $5-\mathrm{HT}_{3}$ receptor antagonists; for IBS-C, the drugs mainly include fiber supplements ,laxative agents, $5-\mathrm{HT}_{4}$ receptor agonists, and prosecretory agents; and for IBS-M, the medications has been described previously.

Western medicine for the treatment of overlap syndrome of FD and IBS could be summarised as Figure 1 .

\subsection{Traditional Chinese Medicine Treatments}

In view of the complexity in the treatment of FD-IBS, the vast majority of gastrointestinal motility drugs having unidirectional regulative effect, and only a few drugs (such as trimebutine and pinaverium bromide) having a bi-directional effect, we must try new approaches of treatment. Accordingly, traditional Chinese medicines have two features. First, there is a treatment method, namely homo 


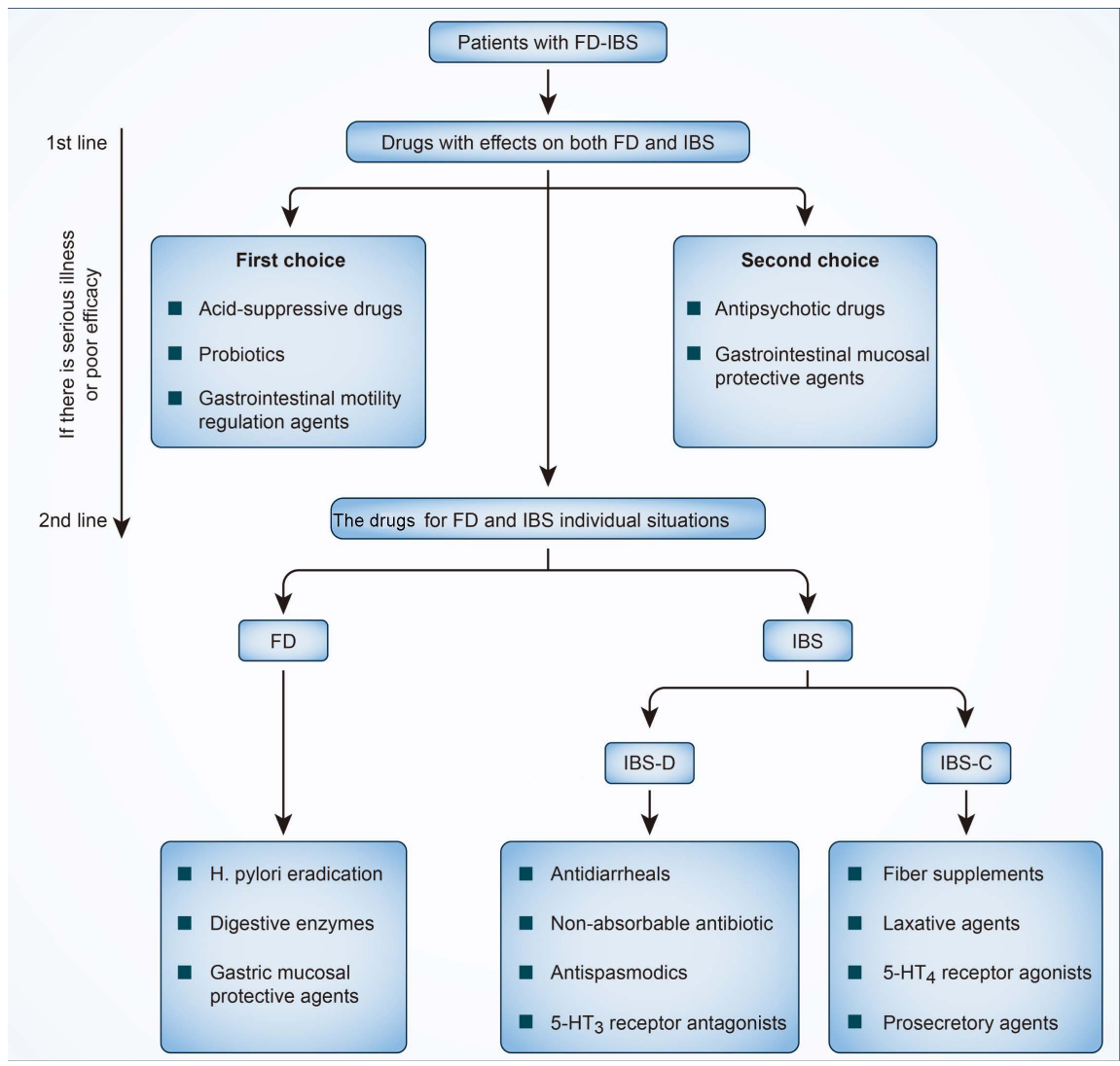

Figure 1. Therapeutic strategies of western medicine for FD-IBS.

therapy for heteropathy [41], which means treating different diseases with same drugs. Secondly, many Chinese herbs have a bidirectional regulative effect [42]. That is to say, according to different body state and/or different ways of medications, the same Chinese medicine and its components may play different roles or even contradictious roles. Therefore, the new treatment methods of FD-IBS can be tried from traditional Chinese medicine or integrated traditional Chinese and western medicines.

It is widely accepted that the basic pathogenesis of both FD and IBS is related to deficiency-weakness of spleen-QI, and Liver-Qi stagnation and spleen. The only difference is that FD is located in the stomach, whereas IBS is located in the intestines [43]. The same or similar pathogenesis provides a theoretical basis for the occurrence of FD-IBS, and guide the clinicians to find the basic principles which is soothing the liver and strengthening the spleen. On the basis of the above basic principles, and through flexible medications, we could modify drugs according to the disease or symptoms [44] [45], avoiding the difficulty of taking into account the upper and lower digestive tract when lacking gastrointestinal motility drugs of bi-directional regulative function. If these can be done, we can, to a certain extent, achieve a balance between the upper and lower digestive tract and the optimal effects.

\section{Conclusion}

The complexity of FD-IBS symptoms and the similarity of FD and IBS in patho- 
genesis, determines that their treatment have many unique aspects. We should simplify the medications, flexibly use gastrointestinal motility regulators, follow the principle of individualization, and give full play to the advantages of traditional Chinese medicine, benefitting the patient.

\section{References}

[1] Ford, A.C., Marwaha, A., Lim, A. and Moyyedi, P. (2011) Systematic Review and Meta-Analysis of the Prevalence of Irritable Bowel Syndrome in Individuals with Dyspepsia. Clinical Gastroenterology and Hepatology, 8, 401-409. https://doi.org/10.1016/j.cgh.2009.07.020

[2] Perveen, I., Rahman, M.M., Saha, M., Raham, M.M. and Hasan, M.Q. (2014) Prevalence of Irritable Bowel Syndrome and Functional Dyspepsia, Overlapping Symptoms, and Associated Factors in a General Population of Bangladesh. Indian Journal of Gastroenterology, 33, 265-273. https://doi.org/10.1007/s12664-014-0447-1

[3] Wang, A., Liao, X., Xiong, L., et al. (2008) The Clinical Overlap between Functional Dyspepsia and Irritable Bowel Syndrome Based on Rome III Criteria. BMC Gastroenterology, 23, 8, 43. https://doi.org/10.1186/1471-230X-8-43

[4] Park, C.S. and Uhm, J.H. (2012) Polymorphisms of the Serotonin Transporter Gene and G-Protein $\beta 3$ Subunit Gene in Korean Children with Irritable Bowel Syndrome and Functional Dyspepsia. Gut and Liver, 6, 223-228.

https://doi.org/10.5009/gnl.2012.6.2.223

[5] Kim, H.I., Jung, S.A., Choi, J.Y., et al. (2013) Impact of Shiftwork on Irritable Bowel Syndrome and Functional Dyspepsia. Journal of Korean Medical Science, 28, 431437. https://doi.org/10.3346/jkms.2013.28.3.431

[6] Fujiwara, Y., Kubo, M., Kohata, Y., et al. (2011) Cigarette Smoking and Its Association with Overlapping Gastroesophageal Reflux Disease, Functional Dyspepsia, or Irritable Bowel Syndrome. Internal Medicine, 50, 2443-2447.

https://doi.org/10.2169/internalmedicine.50.6012

[7] Svedlund, J., Sjodin, I., Dotevall, G. and Gillberg, R. (1985) Upper Gastrointestinal and Mental Symptoms in the Irritable Bowel Syndrome. Scandinavian Journal of Gastroenterology, 20, 595-601. https://doi.org/10.3109/00365528509089702

[8] Camilleri, M. and Tack, J. (2010) Current Medical Treatments of Dyspepsia and Irritable Bowel Syndrome. Gastroenterology Clinics of North America, 39, 481-493. https://doi.org/10.1016/j.gtc.2010.08.005

[9] Savas, L.S., White, D.L., Wieman, M., et al. (2009) Irritable Bowel Syndrome and Dyspepsia among Women Veterans: Prevalence and Association with Psychological Distress. Alimentary Pharmacology \& Therapeutics, 29, 115-125. https://doi.org/10.1111/j.1365-2036.2008.03847.x

[10] Futagami, S., Itoh, T. and Sakamoto, C. (2015) Systematic Review with Meta-Analysis: Post-Infectious Functional Dyspepsia. Alimentary Pharmacology \& Therapeutics, 41,177-188. https://doi.org/10.1111/apt.13006

[11] Kong, J.M. and Bo, P. (2007) The Study on the "Combination of Syndromes" of the Upper Digestive Tract of Irritable Bowel Syndrome. Journal of Clinical Medicine in Practice, 11, 97-99. (In Chinese)

[12] Fan, L.H., Lin, Z.Z. and Liang, P.Y. (2013) The State of Anxiety and Depression in the Patients with Functional Dyspepsia. Chinese Journal of Practical Medicine, 40, 42-45. (In Chinese)

[13] Piacentino, D., Cantarini, R., Alfonsi, M., et al. (2011) Psychopathological Features 
of Irritable Bowel Syndrome Patients with and without Functional Dyspepsia: A Cross Sectional Study. BMC Gastroenterology, 11, 94. https://doi.org/10.1186/1471-230X-11-94

[14] Suzuki, H. and Hibi, T. (2011) Overlap Syndrome of Functional Dyspepsia and Irritable Bowel Syndrome-Are Both Diseases Mutually Exclusive? Journal of Neurogastroenterology and Motility, 17, 360-365.

https://doi.org/10.5056/jnm.2011.17.4.360

[15] Cremonini, F. and Talley, N.J. (2004) Review Article: The Overlap between Functional Dyspepsia and Irritable Bowel Syndrome-A Tale of One or Two Disorders? Alimentary Pharmacology \& Therapeutics, 20, 40-49. https://doi.org/10.1111/j.1365-2036.2004.02184.x

[16] Fujiwara, Y. and Arakawa, T.J. (2014) Overlap in Patients with Dyspepsia/Functional Dyspepsia. Neurogastroenterology \& Motility, 20, 447-457. https://doi.org/10.5056/jnm14080

[17] Talley, N.J. (2006) A Unifying Hypothesis for the Functional Gastrointestinal Disorders: Really Multiple Diseases or one Irritable Gut? Reviews in Gastroenterological Disorders, 6, 72-78.

[18] Dave, B. and Rubin, W. (1999) Inhibition of Gastric Secretion Relieves Diarrhea and Postprandial Urgency Associated with Irritable Bowel Syndrome or Functional Diarrhea. Digestive Diseases and Sciences, 44, 1893-1898. https://doi.org/10.1023/A:1018811226860

[19] Santos, J., Guilarte, M., Alonso, C. and Malagelada, J.R. (2005) Pathogenesis of Irritable Bowel Syndrome: The Mast Cell Connection. Scandinavian Journal of Gastroenterology, 40, 129-140. https://doi.org/10.1080/00365520410009410

[20] Petersen, L.J., Hansen, U., Kristensen, J.K., Nielsen, H., Skov, P.S. and Nielsen, H.J., (1998) Studies on Mast Cells and Histamine Release in Psoriasis: The Effect of Ranitidine. Acta Dermato-Venereologica, 78, 190-193. https://doi.org/10.1080/000155598441503

[21] Dickinson, J.B. (1994) Is Omeprazole Helpful in Inflammatory Bowel Disease? Journal of Clinical Gastroenterology, 18, 317-319. https://doi.org/10.1097/00004836-199406000-00012

[22] Keszthelyi, D., Dackus, G.H., Masclee, GM., Kruimel, J.W. and Masclee, A.A. (2012) Increased Proton Pump Inhibitor and NSAID Exposure in Irritable Bowel Syndrome: Results from a Case-Control Study. BMC Gastroenterology, 12, 121. https://doi.org/10.1186/1471-230X-12-121

[23] Gotteland, M.L., Brunser, O. and Cruchet, S. (2006) Systematic Review: Are Probiotics Useful in Controlling Gastric Colonization by Helicobacter pylori? Alimentary Pharmacology \& Therapeutics, 23, 1077-1086.

https://doi.org/10.1111/j.1365-2036.2006.02868.x

[24] Ianiro, G., Pizzoferrato, M., Franceschi, F., Tarullo, A., Luisi, T. and Gasbarrini, G., (2013) Effect of an Extra-Virgin Olive Oil Enriched with Probiotics or Antioxidants on Functional Dyspepsia: A Pilot Study. European Review for Medical and Pharmacological Sciences, 17, 2085-2090.

[25] Grace, E., Shaw, C., Whelan, K., et al. (2013) Review Article: Small Intestinal Bacterial Overgrowth-Prevalence, Clinical Features, Current and Developing Diagnostic Tests, and Treatment. Alimentary Pharmacology \& Therapeutics, 38, 674688. https://doi.org/10.1111/apt.12456

[26] Zhong, Y.Q., Zhu, J., Guo, J.N., et al. (2007) A Randomized and Case-Control Clinical Study on Trimebutine Maleate in Treating Functional Dyspepsia Coexisting with Diarrhea-Dominant Irritable Bowel Syndrome. Zhonghua Nei Ke Za Zhi, 46, 
899-902.

[27] Delvaux, M. and Wingate, D. (1997) Trimebutine: Mechanism of Action, Effects on Gastrointestinal Function and Clinical Results. Journal of International Medical Research, 25, 225-246. https://doi.org/10.1177/030006059702500501

[28] Lei, J.M. and Wu, W.L. (2012) Application of Pinaverium Bromide Combined with Deanxit in Treatment of Functional Dyspepsia. Chinese Journal of Modern Drug Application, 6, 21 -22. (In Chinese)

[29] López-Alvarenga, J.C., Sobrino-Cossío, S., Remes-Troche, J.M., Chiu-Ugalde, J., Vargas-Romero, J.A. and Schmulson, M. (2013) Polar Vectors as a Method for Evaluating the Effectiveness of Irritable Bowel Syndrome Treatments: An Analysis with Pinaverium Bromide $100 \mathrm{mg}$ plus Simethicone $300 \mathrm{mg}$ po Bid. Revista de Gastroenterología de México, 78, 21-27. https://doi.org/10.1016/j.rgmx.2012.10.003

[30] Grover, M. and Camilleri, M. (2013) Effects on Gastrointestinal Functions and Symptoms of Serotonergic Psychoactive Agents Used in Functional Gastrointestinal Diseases. Journal of Gastroenterology, 48, 177-181.

https://doi.org/10.1007/s00535-012-0726-5

[31] Kinsinger, S.W., Ballou, S. and Keefer, L. (2015) Snapshot of an Integrated Psychosocial Gastroenterology Service. World Journal of Gastroenterology, 21, 1893 1899. https://doi.org/10.3748/wjg.v21.i6.1893

[32] Sheng, P.H. and Li, C.S. (1994) Effect of Marzulene-S on Treatment of Chronic Functional Dyspepsia and Its Dynamics of Disorder. Journal of Clinical Internal Medicine, 11, 27-28. (In Chinese)

[33] Basra, S., Verne, G.N. and Zhou, Q. (2013) Randomized Placebo-Controlled Trial of Glutamine for the Treatment of Diarrhea-Predominant Irritable Bowel Syndrome. Gastroenterology, 144, S160. https://doi.org/10.1016/S0016-5085(13)60577-6

[34] Talley, N.J. and Riff, D.S. (2001) Double-Blind Placebo-Controlled Multicentre Studies of Rebamipide, a Gastroprotective Drug, in the Treatment of Functional Dyspepsia with or without Helicobacter pylori Infection. Alimentary Pharmacology \& Therapeutics, 15, 1603-1611. https://doi.org/10.1046/j.1365-2036.2001.01074.x

[35] Tanigawa, T., Watanabe, T., Otani, K., et al. (2013) Rebamipide Inhibits Indomethacin-Induced Small Intestinal Injury: Possible Involvement of Intestinal Microbiota Modulation by Upregulation of a-Defensin 5. European Journal of Pharmacology, 704, 64-69. https://doi.org/10.1016/j.ejphar.2013.02.010

[36] Niwa, Y., Nakamura, M., Miyahara, R., et al. (2009) Geranylgeranylacetone Protects against Diclofenac-Induced Gastric and Small Intestinal Mucosal Injuries in Healthy Subjects: A Prospective Randomized Placebo-Controlled Double-Blind Cross-Over Study. Digestion, 80, 260-266. https://doi.org/10.1159/000236032

[37] Fang, Y.L. and Zhou, L. (2010) Observation on the Therapeutic Effect of Complex Azintamide in Treatment of Functional Dyspepsia. Chinese Journal of General Practice, 8, 604-605. (In Chinese)

[38] Saad, R.J. and Chey, W.D. (2006) Review Article: Current and Emerging Therapies for functional Dyspepsia. Alimentary Pharmacology \& Therapeutics, 24, 475-492. https://doi.org/10.1111/j.1365-2036.2006.03005.x

[39] Chey, W.D., Maneerattaporn, M. and Saad, R. (2011) Pharmacologic and Complementary and Alternative Medicine Therapies for Irritable Bowel Syndrome. Gut Liver, 5, 253-266. https://doi.org/10.5009/gnl.2011.5.3.253

[40] Camilleri, M. (2014) Novel Therapeutic Agents in Neurogastroenterology: Advances in the Past Year. Neurogastroenterology \& Motility, 26, 1070-1078.

https://doi.org/10.1111/nmo.12386 
[41] Li, J.H., Liu, A.J., Li, H.Q., Wang, Y., Cai, S.H. and Zheng, G.Q. (2014) Buyang Huanwu Decoction for Healthcare: Evidence-Based Theoretical Interpretations of Treating Different Diseases with the Same Method and Target of Vascularity. Evidence-Based Complementary and Alternative Medicine, 2014, Article ID: 506783. https://doi.org/10.1155/2014/506783

[42] Mao, H., Wang, H., Ma, S., et al. (2014) Bidirectional Regulation of Bakuchiol, an Estrogenic-Like Compound, on Catecholamine Secretion. Toxicology and Applied Pharmacology, 274, 180-189. https://doi.org/10.1016/j.taap.2013.11.001

[43] Ren, Y.Q., Zha, A.S. and Gao, H.H. (2009) Pathogenesis Investigation of Irritable Bowel Syndrome Overlapping Functional Dyspepsia. Journal of Liaoning University of TCM, 11, 74-75. (In Chinese)

[44] Zhuang, S. (2004) Yueju Pill in Treating Functional Dyspepsia with Irritable Bowel Syndrome of Liver Depression and Spleen Deficiency Type. Journal of Sichuan of Traditional Chinese Medicine, 22, 50-51. (In Chinese)

[45] Cremonini, F. (2014) Standardized Herbal Treatments on Functional Bowel Disorders: Moving from Putative Mechanisms of Action to Controlled Clinical Trials. Neurogastroenterology \& Motility, 26, 893-900. https://doi.org/10.1111/nmo.12384

\section{Submit or recommend next manuscript to SCIRP and we will provide best} service for you:

Accepting pre-submission inquiries through Email, Facebook, LinkedIn, Twitter, etc. A wide selection of journals (inclusive of 9 subjects, more than 200 journals)

Providing 24-hour high-quality service

User-friendly online submission system

Fair and swift peer-review system

Efficient typesetting and proofreading procedure

Display of the result of downloads and visits, as well as the number of cited articles

Maximum dissemination of your research work

Submit your manuscript at: http://papersubmission.scirp.org/

Or contactym@scirp.org 